\section{Amnesic effects in free recall with introverts and extroverts*}

\author{
ROBERT J. MCLAUGHLIN and STANLEY K. KARY† \\ Southern Illinois University, Edwardsville, Ill. 62025
}

A series of 40 free recall lists with 12 items were presented to each of $80 \mathrm{Ss}$ with either a proper name or a burst of white noise in Position 3,6 , or 10. Forty extroverts and 40 introverts were compared for either recall or recognition of the items. A retrograde amnesia-like effect was found for the item prior to the proper name, but introverts did not show a greater effect as hypothesized. Extroverts and introverts were not differentially affected by the white noise, but the extroverts made more correct responses and errors on the recognition test than did the introverts.

A number of studies have been done to determine the relationship between extroversion-introversion and performance on verbal learning tasks (Howarth \& Eysenck, 1968; Jensen, 1962; McLaughlin, 1968; McLaughlin \& Eysenck, 1967). Much of the interest in this problem stems from a theory proposed by Eysenck (1967). Eysenck postulated that extroverts, functioning at low levels of cortical arousal, complete the consolidation of learning rapidly and do well if tested for immediate recall. Conversely, introverts, functioning at high levels of cortical arousal, continue consolidation over a longer period of time and show poor immediate recall. However, according to the theory, introverts should be superior to extroverts if tested for recall after a delay interval. Jensen (1962), McLaughlin (1968), and McLaughlin \& Eysenck (1967) have shown that extroverts do perform better than introverts on verbal learning tasks. Howarth \& Eysenck (1968), using a paired-associates task, found no differences in learning rates between the two groups; but, on a recall task, they found that, while extroverts showed better immediate recall, the performance of introverts improved dramatically with increasing delay intervals. They also demonstrated that the recall performance of extroverts decreased with increasing delay intervals. McLaughlin (1968) also studied retention over several delay periods but found no differences in the performance of extroverts and introverts on three measures of memory.

Tulving (1969), studying a free recall task, presented Ss with a 15 -item list of common words with an item

* This research was supported by Southern lllinois University Research and Projects Grant 02-04-08.

tPresent address: Psychology Department, Florissant Valley Junior College, Florissant, Mo. 63135 . having a high probability of recall inserted in Position 2, 8, or 14. He found a large decrement in a S's ability to recall the item prior to the high-probability item. This effect he compared to the retrograde amnesia produced in animals by electroconvulsive shock. Retrograde amnesia is thought to be the result of the disruption of consolidation processes. This phenomenon, demonstrated in a verbal learning task, provides a means of testing the hypothesis that extroverts and introverts differ in amount of time required for consolidation. Extroverts, who are theorized to complete consolidation rapidly, should show less of an amnesic reaction to a high-probability item than introverts. The present study is an attempt to test this hypothesis. To achieve a closer parallel to the electroconvulsive shock used to induce retrograde amnesia effectively in animals, the effect of a brief intense burst of white noise was assessed to determine if it could produce an equivalent or greater amount of retrograde amnesia than the measure was used in addition to the strength of the phenomenon.

\section{SUBJECTS}

The Ss were 80 volunteer undergraduate students between 18 and 25 years of age. On the basis of the Eysenck Personality Inventory (Eysenck \& Eysenck, 1964), the Ss were divided into two groups: extroverts and introverts. Ss scoring in the middle range (11-13) on the introversion-extroversion scale were excluded from the sample. Scores on the neuroticism scale were taken into account, and the two groups were matched on this dimension. This was done so that the results of the study could not be attributed to differences in neuroticism rather than to differences in extroversionhigh-probability item. A recognition more common recall measure to provide a more sensitive index of the introversion. There were 40 Ss in each of the two groups. Half of the $S s$ in each group were assigned randomly to a recall testing procedure, while the other half were assigned to a recognition testing procedure. MATERIALS

Three types of list were used: control, proper name, and noise. The 10 control lists each consisted of 12 randomly selected high-frequency common words (Thorndike \& Lorge, 1944). The 15 proper name lists were identical to the control lists, except that the item in Position 3,6 , or 10 was replaced with the name of a famous person (e.g., Napoleon, Freud). The 15 noise lists were also identical to the control lists, except that the item in Position 3, 6, or 10 was replaced with a .75 -sec burst of 100-dB white noise. For both the proper name and noise lists, there were 5 lists with the replacement item in the $3 \mathrm{rd}$ position, 5 with the replacement item in the 6 th position, and 5 with the replacement item in the 10th position. Thus, there was only one replacement per list. The control and proper name lists were similar in construction to those used by Tulving (1969). Each list was presented aurally using a tape recorder and earphones at the rate of 1 word/sec.

\section{PROCEDURE}

Each $\mathrm{S}$ was tested individually on all 40 lists. Counterbalancing of the order of the lists was done both within and between Ss. Two practice lists for each of the three types of list were given prior to the beginning of the task. The 40 Ss tested with the recall procedure were instructed to learn as many of the words as possible. After each list was presented, the $S$ was given $30 \mathrm{sec}$ to write as many responses as he could recall. The Ss tested with the recognition procedure were also instructed to learn as many of the words as possible. After each list was presented, the $\mathrm{S}$ was given a sheet with 30 words in 3 columns and 10 rows. The $\mathrm{S}$ was given $30 \mathrm{sec}$ to indicate which words had been presented. The filler words were from the same sample of words but had not been used in any of the lists. At the end of the 30 -sec recall or recognition period, a mild tone signaled the $S$ to stop writing and prepare for the next list. A 2 -min rest period was given after each block of 10 lists.

\section{RESULTS}

The mean number of correct responses before, after, and including the critical item for the three types of lists is presented in Table 1. A 2 by 2 by 3 by 3 analysis of variance was done with two types of testing procedures (recall and recognition), two personality groups (extroverts and introverts), three types of list (proper 
Table 1

Mean Number of Correct Responses of a Maximum of Five on the Control Lists and for the ltems Before and After the Proper Name or Noise

\begin{tabular}{|c|c|c|c|c|c|c|c|c|c|}
\hline & \multicolumn{9}{|c|}{ Item Position } \\
\hline & 2 & 3 & 4 & 5 & 6 & 7 & 9 & 10 & 11 \\
\hline \multicolumn{10}{|l|}{ Recall } \\
\hline Control & 1.15 & .70 & 1.05 & .75 & .60 & .75 & 2.10 & 2.95 & 4.10 \\
\hline Name $3,6,10$ & 1.60 & 3.60 & 1.10 & .50 & 3.65 & .70 & 1.60 & 4.45 & 3.80 \\
\hline Noise $3,6,10$ & 1.85 & - & 1.15 & $\mathbf{1 . 1 5}$ & - & 1.40 & 2.50 & - & 4.20 \\
\hline \multicolumn{10}{|l|}{ Recognition } \\
\hline Control & 2.90 & 3.70 & 3.40 & 3.05 & 3.40 & 3.55 & 4.10 & 3.60 & 3.65 \\
\hline Same $3,6,10$ & 3.70 & 4.80 & 3.35 & 2.90 & 4.70 & 3.10 & 3.25 & 4.80 & 4.20 \\
\hline Soise $3,6,10$ & 4.05 & - & 3.60 & 3.40 & - & 4.05 & 3.60 & - & 4.00 \\
\hline
\end{tabular}

name, noise, and control), and three item positions $(2,5$, and 9$)$. The analysis compared number of correct responses at each item position before a critical item to the number of correct responses on the control lists at that same position. The results of the analysis showed significant main effects for type of testing, type of list, and item position. The recognition procedure resulted in better performance than did the recall procedure $(F=261.66$, df $=1 / 76$, $p<.001)$. The main effect of type of list (proper name, noise, and control) was significant $(\mathrm{F}=16.94, \mathrm{df}=2 / 152$, p $<.01)$. A Duncan's test showed that there were no differences between the noise and control lists, but that the proper name list showed a significant amnesic effect $(p<.01)$. The main effect of item position was also significant $(F=37.75, \mathrm{df}=2 / 152$, $p<.01)$. A Duncan's test showed that It em Position 5 resulted in significantly lower recall and recognition than did Item Positions 2 and $9 \quad(p<.01)$. Item Position 9 resulted in the highest scores and was significantly better than Item Position 2, which was intermediate $(\mathrm{p}<.01)$.

Three interactions were found to be significant. The Type of Testing by Item Position interaction ( $F=8.26, \mathrm{df}$ $=2 / 152, \mathrm{p}<.01)$ indicated that recognition resulted in somewhat similar retention scores for each position, while recall resulted in greatest recall for Item Position 9, less for 2 , and poorest recall for 5 . The Item Position by Type of List interaction $(\mathrm{F}=9.28, \mathrm{df}=4 / 304$, $p<.01)$ showed that for all the noise and name items, retention for Positions 2 and 9 was similar, while that for Position 5 was much poorer. For the control items, Item Position 2 was poorer than the other two types of items and at Position 9 it resulted in better performance. This interaction indicates the lack of an amnesic effect at Item Position 2 but a large amnesic effect at Item Position 9. The interaction of Type of Testing by Item Position by Type of List was significant $(F=4.13, \mathrm{df}=4 / 304$, $p<.01)$. This interaction indicated that the recall procedure with items before the names produced the greatest amnesic effect, especially Item Positions 5 and 9.

With respect to personality differences, the analysis showed no significant main effects or interactions. There was, however, one measure on which the personality groups did differ. On the recognition testing procedure, the extroverts were combined, the extroverts made an average of 8.95 correct responses on each list, while the introverts made only 7.87 correct responses. An analysis of variance indicated that this difference was significant $(F=9.63$, df $=1 / 36, \mathrm{p}<.005$ ). This superiority of the extroverts on the recognition testing procedure was, however, associated with their tendency to make more errors on the recognition task. For all lists combined, the extroverts made an average of 3.97 errors on each list, while the introverts made only 2.36 errors. This difference was also significant $(F=5.89, \mathrm{df}=$ $1 / 36, p<.025$ ). Thus, the extroverts did better on the recognition task, but only at the expense of making more errors. For the recall testing procedure, the two groups did not differ in performance.

\section{DISCUSSION}

The present study did find evidence of a retrograde amnesia-like effect for two of the item positions using a proper name as the critical item. However, the results did not show the effect to be equivalent in magnitude to that obtained by Tulving (1969). Other studies have also investigated the facilitating or debilitating effect of an isolated item in a free recall list. Wallace (1965), in a review of the von Restorff phenomenon, cited several studies that have yielded conflicting results. Some have found a facilitating effect for recall of the item prior to, and immediately following, the isolated item. None of the six studies that Wallace (1965) reviewed demonstrated a debilitating effect for recall of the item immediately prior to the isolated item. Ellis, Detterman, superior to the introverts. For all lists
Runcie, McCarver, \& Craig (1971) studied the same phenomenon using photographs of nudes as the high-probability recall item and found that the photograph presented at Position 15 resulted in no retrograde amnesia effect but did result in a profound antegrade amnesia effect. In view of the inconsistencies in the results of these studies, the analogy that Tulving (1969) draws between this type of task and its counterpart, used in studying retrograde amnesia in animals, may not be entirely accurate. The present study, in particular, shows little evidence for the disruption of consolidation processes brought on by a burst of white noise, which is probably more equivalent to electroconvulsive shock than is a proper name.

The results of the study indicated that there were no personality differences in Ss' abilities to recall or recognize an item preceding a high-probability item. However, this is not to say that differences between introverts and extroverts could not be demonstrated if this retrograde amnesia-like effect could be produced consistently and with a greater magnitude than was demonstrated in the present study. This study used a 1 -sec rate of presentation, which might not have allowed sufficient time for a differential consolidation rate to occur between the two personality groups. Perhaps a 2 - or 3 -sec rate would have produced the predicted differerıces. Considering the lack of a consistent amnesic effect with this task, varying the time interval alone would not likely be as appropriate as altering the nature of the task itself. Personality differences were found on the recognition task. Error scores for the extroverts indicated a greater willingness to "guess" when they thought they might possibly be correct. In a previous study (McLaughlin, 1968), extroverts were found to learn response items in a paired-associates list faster than introverts. This was interpreted as being indicative of their tendency to be less cautious about being incorrect. This conclusion is supported by the data from the present study.

\section{REFERENCES}

ELLIS, N. R., DETTERMAN, D. K., RUNCIE, D., MCCARVER, R. B., \& CRAIG. E. M. Amnesic effects in short-term memory. Journal of Experimental Psychology, 1971, 89, 357-361.

EYSENCK, H. J. The biological basis of personality. Springfield, Ill: Thomas, 1967

EYSENCK, H. J., \& EYSENCK, S. B. G. Manual of the Evsencl Personality. Incentory. London: University of London Press, 1964.

HOWARTH, E., \& EYSENCK, H I 
Extraversion, arousal and paired-associates recall. Journal of Experimental Research in Personality, $1968,3,114-116$

JENSEN, A. R. Extraversion, neuroticism and serial learning. Acta Psychologica. $1962,20,66-67$.

M CLAUGHLIN, R. J. Retention in paired-associate learning related to extraversion and neuroticism. Psychonomic Science. 1968, 13,333-334. MCLAUGHLIN, R. J., \& EYSENCK, H, J Extroversion, neuroticism and paired-associates learning. Journal of Experimental Research in Personality, $1967,2,128 \cdot 132$.

THORNDIKE, E. L., \& LORGE, I. The teacher's word book of 30,000 words.
New York: Bureau of Publications, Teachers College, Columbia University. 1944.

TULVING, E Retrograde amnesia in free recall. Science, $1969,164,88-90$.

WALLACE, W. P. Review of the historical, empirical, and theoretical status of the von Restorff phenomenon. Psychological Bulletin, $1965,63,410-424$. 